\title{
Mathematical Formulas for Prion All Cross-Structures Listed in the Protein Data Bank
}

\section{Jiapu Zhang ${ }^{1,2^{*}}$}

${ }^{1}$ Molecular Model Discovery Laboratory, Department of Chemistry and Biotechnology, Faculty of Science, Engineering and Technology, Swinburne University of Technology, Hawthorn Campus, Hawthorn, Victoria 3122, Australia

${ }^{2}$ Graduate School of Sciences, Information Technology and Engineering and Centre of Informatics and Applied Optimisation, Faculty of Science and Technology, The Federation University Australia, Mount Helen Campus, Mount Helen, Ballarat, Victoria 3353, Australia

\begin{abstract}
Prion protein $(\operatorname{PrP})$ has two regions: unstructured region $\operatorname{PrP}(1-120)$ and structured region $\operatorname{PrP}(119-231)$. In the structured region, there are many segments which have the property of amyloid fibril formation. By theoretical calculations, $\operatorname{PrP}(126-133), \operatorname{PrP}(137-143), \operatorname{PrP}(170-175), \operatorname{PrP}(177-182), \operatorname{PrP}(211-216)$ have the amyloid fibril forming property. $\operatorname{Pr} P(142-166)$ has a X-ray crystallography experimental $\beta$-hairpin structure, instead of a pure cross- $\beta$ amyloid fibril structure; thus we cannot clearly find it by our theoretical calculations. However, we can predict that there must be a laboratory X-ray crystal structure in $\operatorname{PrP}(184-192)$ segment that will be produced in the near future. The experiments of $\mathrm{X}$-ray crystallography laboratories are agreeing with our theoretical calculations. This article summarized mathematical formulas of prion amyloid fibril cross- $\beta$ structures of all the above PrP segments currently listed in the Protein Data Bank.
\end{abstract}

Keywords: PrP structured region; Amyloid fibril formation peptides; Theoretical calculations; Experimental laboratories; Mathematical formulas

Table 1 lists the cross- $\beta$ structures of all PrP segments that were listed in the Protein Data Bank (PDB, www.rcsb.org), produced by $\mathrm{X}$-ray crystallography experiments. In the below, $1-24$ give some mathematical formulas to describe all these cross- $\beta$ structures.

1. Figure 1, the mathematical formula for B Chain got from A Chain is

$$
B=\left(\begin{array}{lll}
-1 & 0 & 0 \\
0 & 1 & 0 \\
0 & 0 & -1
\end{array}\right) A+\left(\begin{array}{c}
0 \\
4.8655 \\
0
\end{array}\right)
$$

\begin{tabular}{|c|c|c|c|}
\hline PrP segment & Species & PDB ID & Class of the cross $-\beta$ \\
\hline $1 \operatorname{PrP}(126-131)$ & human & 4TUT & Class $7[1,4]$ \\
\hline 2 & human & 4UBY & Class $8^{[1,4]}$ \\
\hline 3 & human & 4UBZ & Class $8^{[1,4]}$ \\
\hline $4 \operatorname{PrP}(126-132)$ & human & $4 \mathrm{~W} 5 \mathrm{~L}$ & Class $8^{[1,4]}$ \\
\hline 5 & human & $4 \mathrm{~W} 5 \mathrm{M}$ & Class $8^{[1,4]}$ \\
\hline 6 & human & $4 \mathrm{~W} 5 \mathrm{P}$ & Class $8^{[1,4]}$ \\
\hline $7 \operatorname{PrP}(127-133)$ & human & $4 W 5 Y$ & Class $6^{[1,4]}$ \\
\hline 8 & human & $4 W 67$ & Class $6^{[1,4]}$ \\
\hline 9 & human & $4 W 71$ & Class $6^{[1,4]}$ \\
\hline $10 \operatorname{PrP}(127-132)$ & human & $4 \mathrm{WBU}$ & Class $8^{[1,4]}$ \\
\hline 11 & human & 4WBV & Class $8^{[1,4]}$ \\
\hline 12 & human & 3MD4 & antiparallel $(P \quad 2,2,2,1)$ \\
\hline 13 & human & 3MD5 & parallel $(P \quad 12,1)$ \\
\hline 14 & human-M129 & $3 \mathrm{NHC}$ & Class $8^{[1]}$ \\
\hline 15 & human-V129 & $3 \mathrm{NHD}$ & Class $8^{[1]}$ \\
\hline $16 \operatorname{PrP}(137-142)$ & mouse & $3 N V G$ & Class $1^{[1]}$ \\
\hline $17 \operatorname{PrP}(137-143)$ & mouse & $3 \mathrm{NVH}$ & Class $1^{[1]}$ \\
\hline $18 \operatorname{PrP}(138-143)$ & $\begin{array}{l}\text { Syrian } \\
\text { hamster }\end{array}$ & $3 N V E$ & Class $6^{[1]}$ \\
\hline 19 & human & $3 N V F$ & Class $1^{[1]}$ \\
\hline $20 \operatorname{PrP}(142-166)$ & sheep & $1 \mathrm{G} 04$ & $\beta$-hairpin ${ }^{[3]}$ \\
\hline $21 \operatorname{PrP}(170-175)$ & human & $2 \mathrm{OL9}$ & Class $2^{[1]}$ \\
\hline 22 & elk & 3FVA & Class $1^{[1]}$ \\
\hline $\begin{array}{l}23 \operatorname{PrP}(177-182, \\
211-216)\end{array}$ & human & 4E1I & $\beta$-prism I fold ${ }^{[2]}\left(\mathrm{P} 2,2,2,{ }_{1}\right)$ \\
\hline 24 & human & 4E1H & $\beta$-prism I fold ${ }^{[2]}\left(\mathrm{P} 2,2,2,{ }_{1}\right)$ \\
\hline
\end{tabular}

Table 1: The cross- $\beta$ structures known in the PDB Bank of PrP segments.

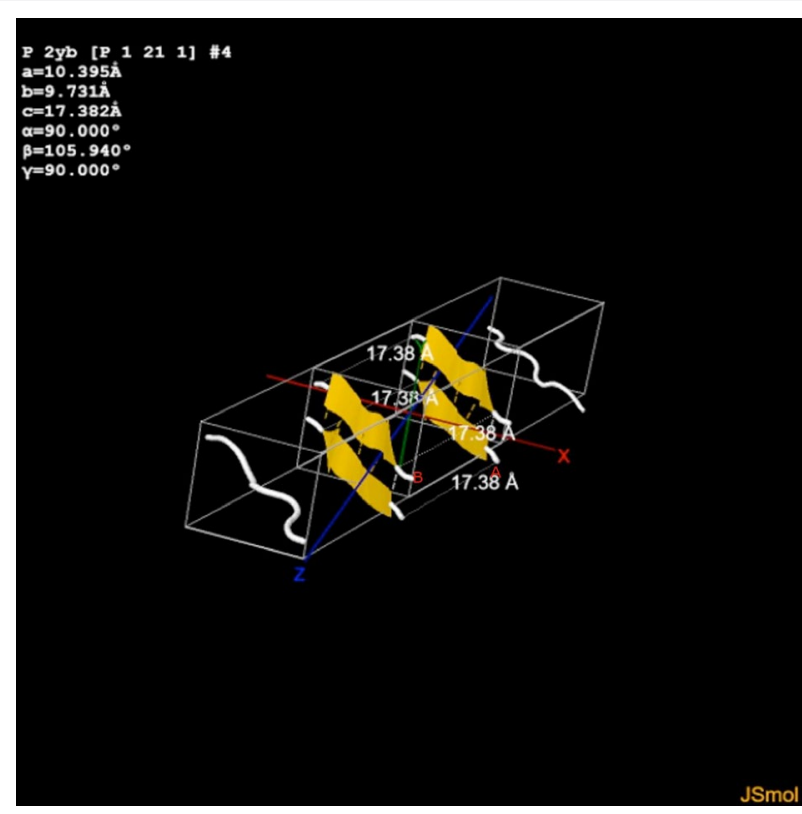

Figure 1: Protein fibril structure of human M129 prion GGYMLG (126-131) (PDB ID: 4TUT). The dashed lines denote the hydrogen bonds. A, B, C, D denote the chains of the fibril.

2. Figure 2, mathematical formulas for EFGH, IJKL, MNOP Chains obtained from $\mathrm{ABCD}$ Chains respectively are

*Corresponding author: Jiapu Zhang, Molecular Model Discovery Laboratory, Department of Chemistry and Biotechnology, Faculty of Science, Engineering and Technology, Swinburne University of Technology, Hawthorn Campus, Hawthorn, Victoria 3122, Australia, Tel: +61-3-92145596/+61-3-53276335; E-mail: jiapuzhang@swin.edu.au/j.zhang@federation.edu.au

Received February 20, 2016; Accepted March 29, 2016; Published March 31 2016

Citation: Zhang J (2016) Mathematical Formulas for Prion All Cross-Structures Listed in the Protein Data Bank. Med chem (Los Angeles) 6: 179-188. doi:10.4172/2161-0444.1000343

Copyright: (c) 2016 Zhang J. This is an open-access article distributed under the terms of the Creative Commons Attribution License, which permits unrestricted use, distribution, and reproduction in any medium, provided the original author and source are credited. 


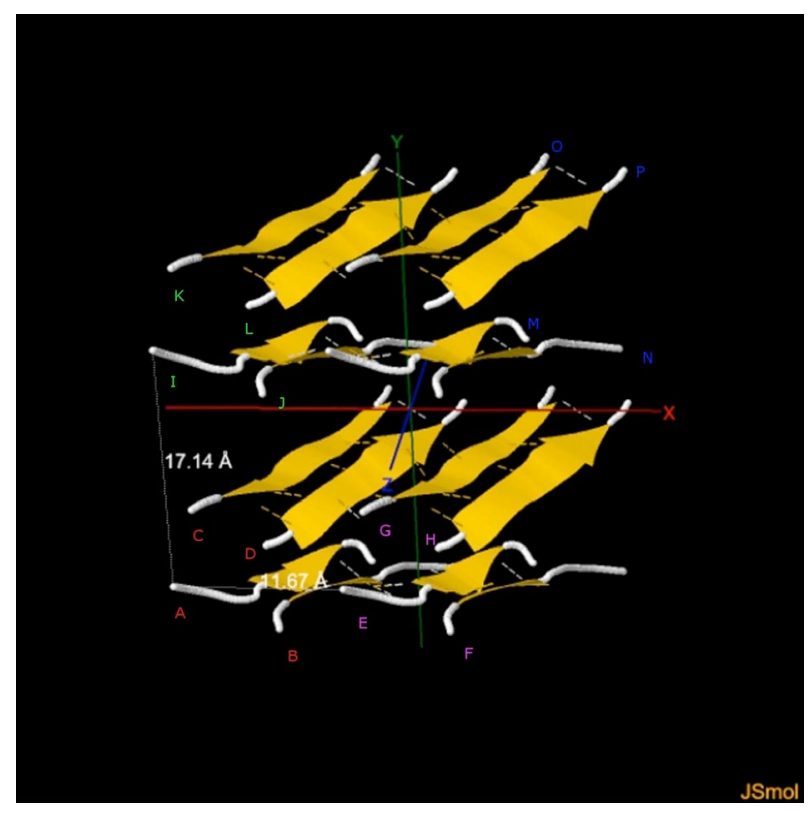

Figure 2: Protein fibril structure of human V129 prion GGYVLG (126-131) (PDB ID: 4UBY). The dashed lines denote the hydrogen bonds. A, B, C, D denote the chains of the fibril.

$$
\begin{aligned}
& E(F / G / H)=\left(\begin{array}{lll}
1 & 0 & 0 \\
0 & 1 & 0 \\
0 & 0 & 1
\end{array}\right) A(B / C / D)+\left(\begin{array}{c}
11.666 \\
0 \\
0
\end{array}\right), \\
& I(J / K / L)=\left(\begin{array}{lll}
1 & 0 & 0 \\
0 & 1 & 0 \\
0 & 0 & 1
\end{array}\right) A(B / C / D)+\left(\begin{array}{c}
-0.05985 \\
17.1449 \\
0
\end{array}\right), \\
& M(N / O / P)=\left(\begin{array}{lll}
1 & 0 & 0 \\
0 & 1 & 0 \\
0 & 0 & 1
\end{array}\right) A(B / C / D)+\left(\begin{array}{c}
11.60615 \\
17.1449 \\
0
\end{array}\right) .
\end{aligned}
$$

3. Figure 3, mathematical formulas for CD, EF, GH, IJ, KL Chains obtained from $\mathrm{AB}$ Chains respectively are

$$
\begin{aligned}
& C(D)=\left(\begin{array}{lll}
1 & 0 & 0 \\
0 & 1 & 0 \\
0 & 0 & 1
\end{array}\right) A(B)+\left(\begin{array}{c}
11.609 \\
0 \\
0
\end{array}\right), \\
& E(F) / I(J)=\left(\begin{array}{lll}
-1 & 0 & 0 \\
0 & 1 & 0 \\
0 & 0 & -1
\end{array}\right) A(B)+\left(\begin{array}{c} 
\pm 9.0535 \\
0
\end{array}\right), \\
& G(H) / K(L)=\left(\begin{array}{lll}
-1 & 0 & 0 \\
0 & 1 & 0 \\
0 & 0 & -1
\end{array}\right) A(B)+\left(\begin{array}{c}
11.609 \\
\pm 9.0535 \\
0
\end{array}\right) .
\end{aligned}
$$

4. Figure 4, mathematical formulas for CD, EF, GH, IJ, KL Chains obtained from the basic $\mathrm{AB}$ Chains respectively are

$$
C(D)=\left(\begin{array}{lll}
1 & 0 & 0 \\
0 & 1 & 0 \\
0 & 0 & 1
\end{array}\right) A(B)+\left(\begin{array}{c}
0 \\
0 \\
9.429
\end{array}\right) \text {, }
$$

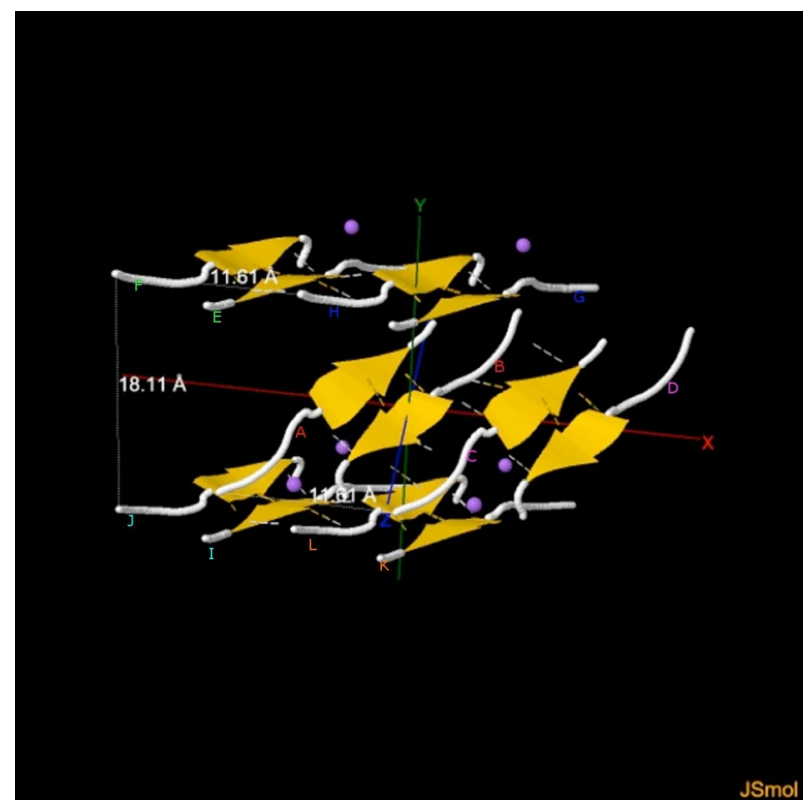

Figure 3: Protein fibril structure of human L129 prion GGYLLG (126-131) (PDB ID: 4UBZ). The dashed lines denote the hydrogen bonds. A, B denote the basic chains of the fibril.

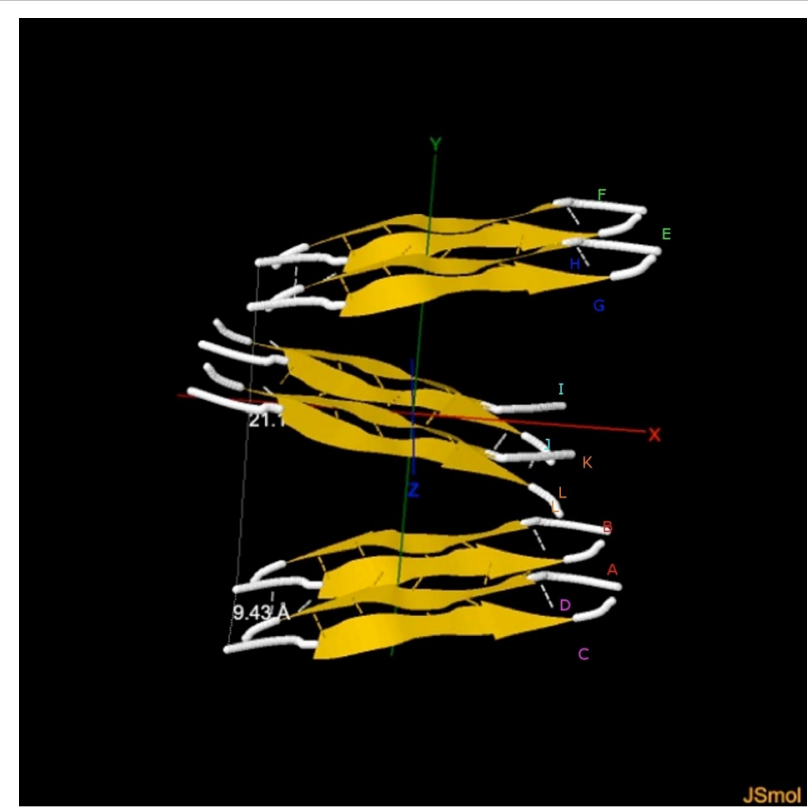

Figure 4: Protein fibril structure of human L129 prion GGYLLGS (126-132) (PDB ID: 4W5L). The dashed lines denote the hydrogen bonds. A, B denote the basic chains of the fibril.

$$
\begin{aligned}
& E(F)=\left(\begin{array}{lll}
1 & 0 & 0 \\
0 & 1 & 0 \\
0 & 0 & 1
\end{array}\right) A(B)+\left(\begin{array}{c}
0 \\
21.113 \\
0
\end{array}\right), \\
& G(H)=\left(\begin{array}{lll}
1 & 0 & 0 \\
0 & 1 & 0 \\
0 & 0 & 1
\end{array}\right) A(B)+\left(\begin{array}{c}
0 \\
21.113 \\
9.429
\end{array}\right),
\end{aligned}
$$




$$
\begin{aligned}
& I(J)=\left(\begin{array}{lll}
-1 & 0 & 0 \\
0 & 1 & 0 \\
0 & 0 & -1
\end{array}\right) A(B)+\left(\begin{array}{c}
25.2415 \\
10.5565 \\
0
\end{array}\right), \\
& K(L)=\left(\begin{array}{lll}
-1 & 0 & 0 \\
0 & 1 & 0 \\
0 & 0 & -1
\end{array}\right) A(B)+\left(\begin{array}{c}
25.2415 \\
10.5565 \\
9.429
\end{array}\right) . \\
& K(L)=\left(\begin{array}{lll}
1 & 0 & 0 \\
0 & -1 & 0 \\
0 & 0 & -1
\end{array}\right) A(B)+\left(\begin{array}{c}
25.2415 \\
10.5565 \\
0
\end{array}\right) .
\end{aligned}
$$

5. Figure 5, mathematical formulas for CD, EF, GH, IJ Chains obtained from the basic $\mathrm{AB}$ Chains respectively are

$$
\begin{aligned}
& C(D) / I(J)=\left(\begin{array}{lll}
-1 & 0 & 0 \\
0 & 1 & 0 \\
0 & 0 & -1
\end{array}\right) A(B)+\left(\begin{array}{c}
25.2415 \\
\pm 4.7185 \\
0
\end{array}\right), \\
& E(F) / G(H)=\left(\begin{array}{lll}
-1 & 0 & 0 \\
0 & 1 & 0 \\
0 & 0 & -1
\end{array}\right) A(B)+\left(\begin{array}{c}
21.69816 \\
\pm 4.7185 \\
22.52862
\end{array}\right) .
\end{aligned}
$$

$$
\left(\begin{array}{lll}
1 & 0 & 0 \\
0 & 1 & 0 \\
0 & 0 & 1
\end{array}\right) A(B)+\left(\begin{array}{c}
23.7405 \\
4.7185 \\
0
\end{array}\right) .
$$

6. Figure 6, mathematical formulas for $\mathrm{CD}$, EF, GH Chains obtained from the basic $\mathrm{AB}$ Chains respectively are

$$
C(D)=\left(\begin{array}{lll}
1 & 0 & 0 \\
0 & 1 & 0 \\
0 & 0 & 1
\end{array}\right) A(B)+\left(\begin{array}{c}
11.593 \\
0 \\
0
\end{array}\right),
$$

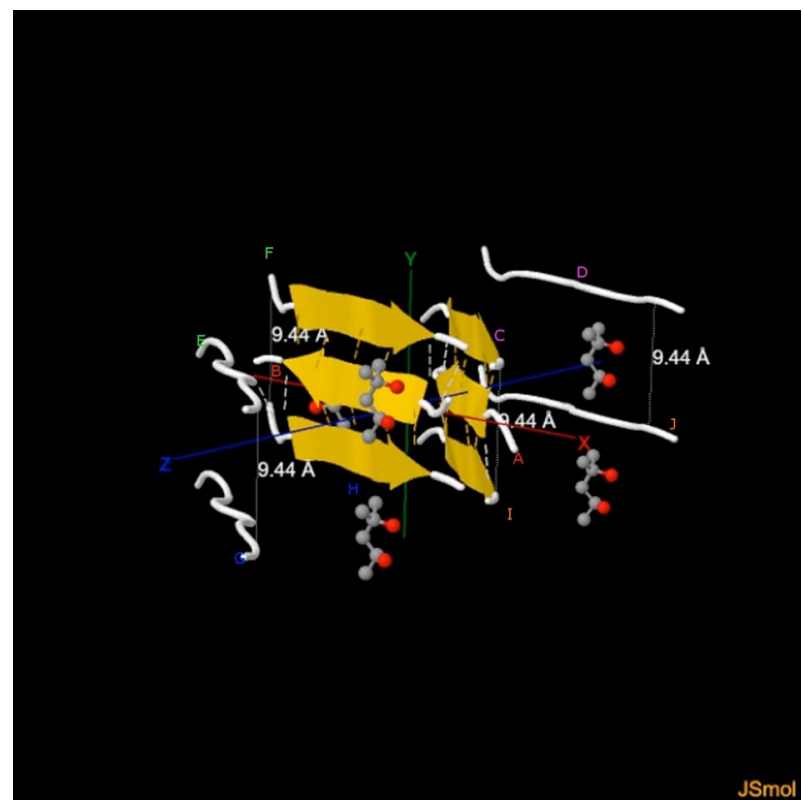

Figure 5: Protein fibril structure of human M129 prion GGYMLGS (126-132) (PDB ID: 4W5M). The dashed lines denote the hydrogen bonds. A, B denote the basic chains of the fibril.

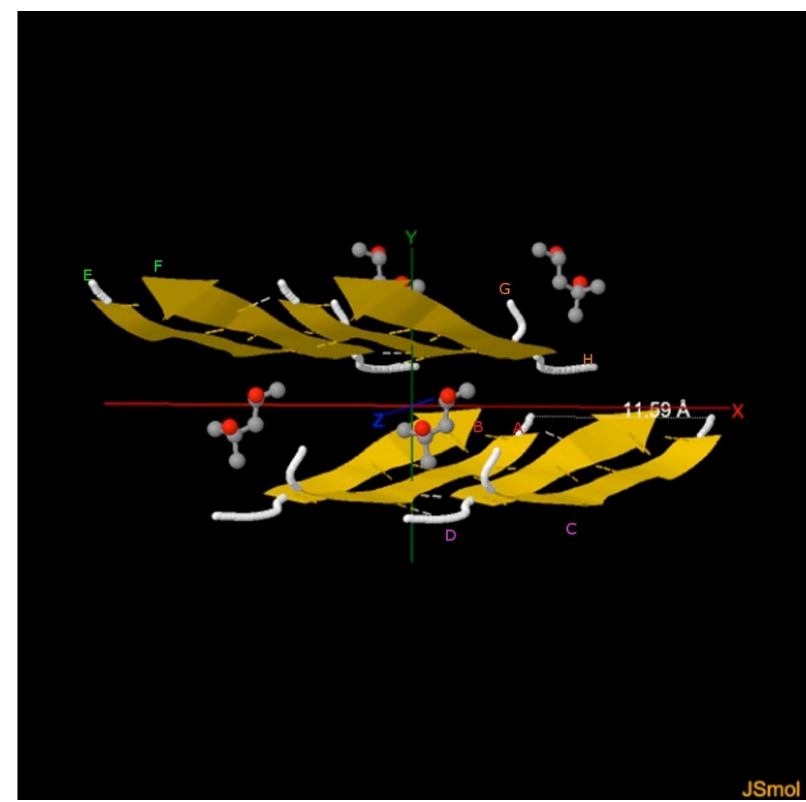

Figure 6: Protein fibril structure of human V129 prion GGYVLGS (126-132) (PDB ID: 4W5P). The dashed lines denote the hydrogen bonds. A, B, C, D, E, F, G, H denote the chains of the fibril.

$$
\begin{aligned}
& E(F)=\left(\begin{array}{lll}
-1 & 0 & 0 \\
0 & 1 & 0 \\
0 & 0 & -1
\end{array}\right) A(B)+\left(\begin{array}{c}
0 \\
8.576 \\
0
\end{array}\right), \\
& G(H)=\left(\begin{array}{lll}
-1 & 0 & 0 \\
0 & 1 & 0 \\
0 & 0 & -1
\end{array}\right) A(B)+\left(\begin{array}{c}
11.593 \\
8.576 \\
0
\end{array}\right) .
\end{aligned}
$$

7. Figure 7, mathematical formulas for CD, EF, G H Chains obtained from the basic $\mathrm{AB}$ Chains respectively are

$$
\begin{aligned}
& C(D)=\left(\begin{array}{lll}
1 & 0 & 0 \\
0 & 1 & 0 \\
0 & 0 & 1
\end{array}\right) A(B)+\left(\begin{array}{c}
9.467 \\
0 \\
0
\end{array}\right), \\
& E(F)=\left(\begin{array}{lll}
1 & 0 & 0 \\
0 & 1 & 0 \\
0 & 0 & 1
\end{array}\right) A(B)+\left(\begin{array}{c} 
\pm 4.12073 \\
\pm 9.59126 \\
0
\end{array}\right), \\
& G=\left(\begin{array}{lll}
1 & 0 & 0 \\
0 & 1 & 0 \\
0 & 0 & 1
\end{array}\right) A+\left(\begin{array}{c}
13.58773 \\
\pm 9.59126 \\
0
\end{array}\right), \\
& H=\left(\begin{array}{lll}
1 & 0 & 0 \\
0 & 1 & 0 \\
0 & 0 & 1
\end{array}\right) B+\left(\begin{array}{c}
5.34627 \\
-9.59126 \\
0
\end{array}\right) .
\end{aligned}
$$

8. Figure 8, mathematical formulas for $\mathrm{CD}, \mathrm{EF}, \mathrm{GH}$ Chains obtained from the basic $\mathrm{AB}$ Chains respectively are

$C(D)=\left(\begin{array}{lll}1 & 0 & 0 \\ 0 & 1 & 0 \\ 0 & 0 & 1\end{array}\right) A(B)+\left(\begin{array}{c}8.519 \\ 0 \\ 0\end{array}\right)$, 


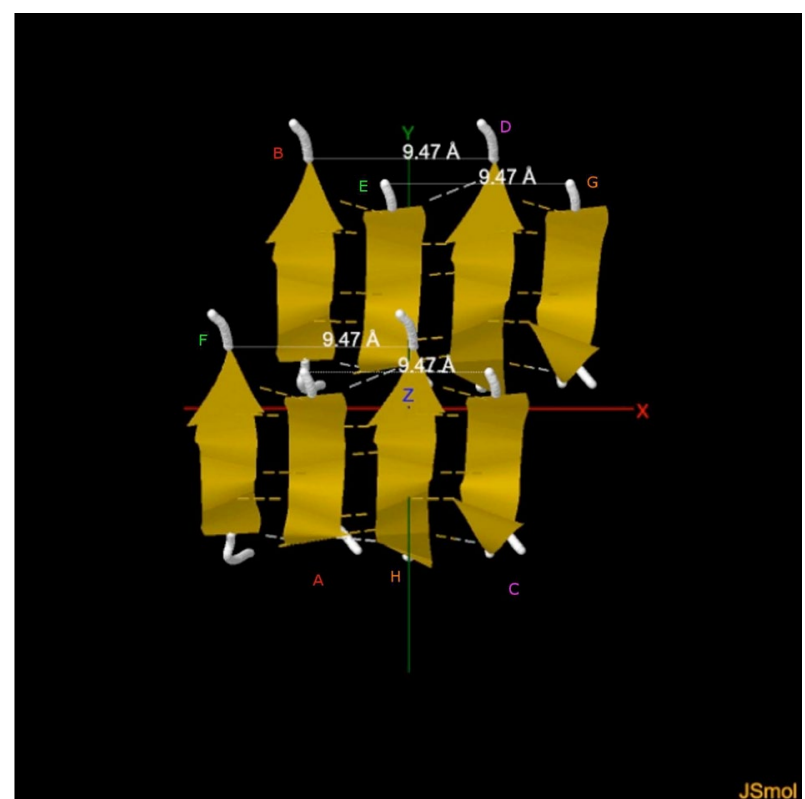

Figure 7: Protein fibril structure of human M129 prion GYMLGSA (127-133) (PDB ID: 4W5Y). The dashed lines denote the hydrogen bonds. A, B denote the basic chains of the fibril.

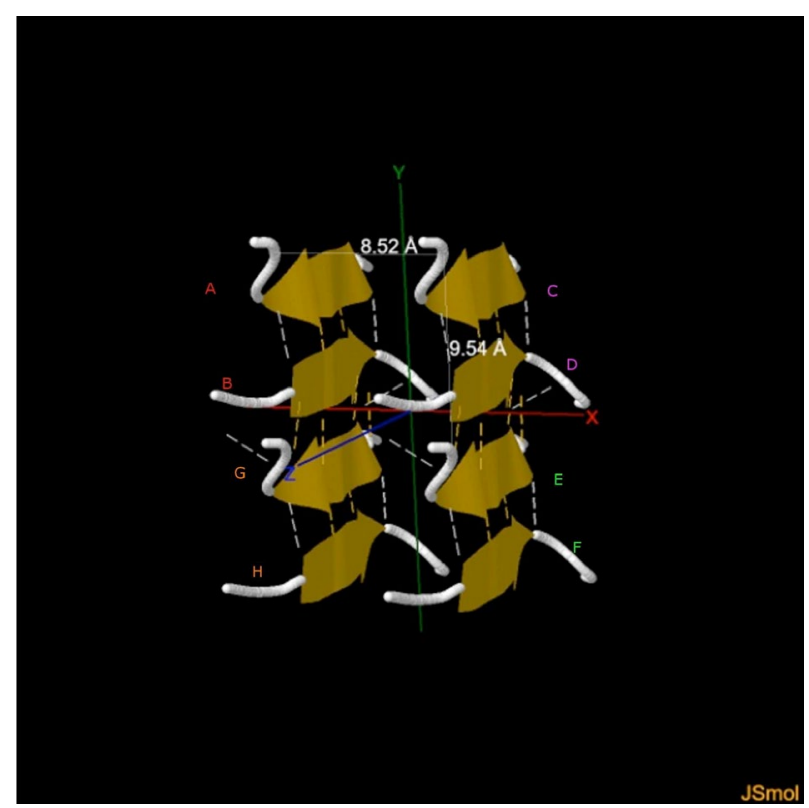

Figure 8: Protein fibril structure of human V129 prion GYVLGSA (127-133) (PDB ID: 4W67). The dashed lines denote the hydrogen bonds. A, B denote the basic chains of the fibril.

$$
E(F)(/ G(H))=\left(\begin{array}{lll}
1 & 0 & 0 \\
0 & 1 & 0 \\
0 & 0 & 1
\end{array}\right) A(B)+\left(\begin{array}{c}
8.53565(/ 0.01665) \\
-9.53999 \\
0
\end{array}\right),
$$

9. Figure 9, mathematical formulas for $\mathrm{CD}, \mathrm{EF}, \mathrm{GH}$ Chains obtained from the basic $\mathrm{AB}$ Chains respectively are

$$
C(D)=\left(\begin{array}{lll}
1 & 0 & 0 \\
0 & 1 & 0 \\
0 & 0 & 1
\end{array}\right) A(B)+\left(\begin{array}{c}
9.467 \\
0 \\
0
\end{array}\right),
$$

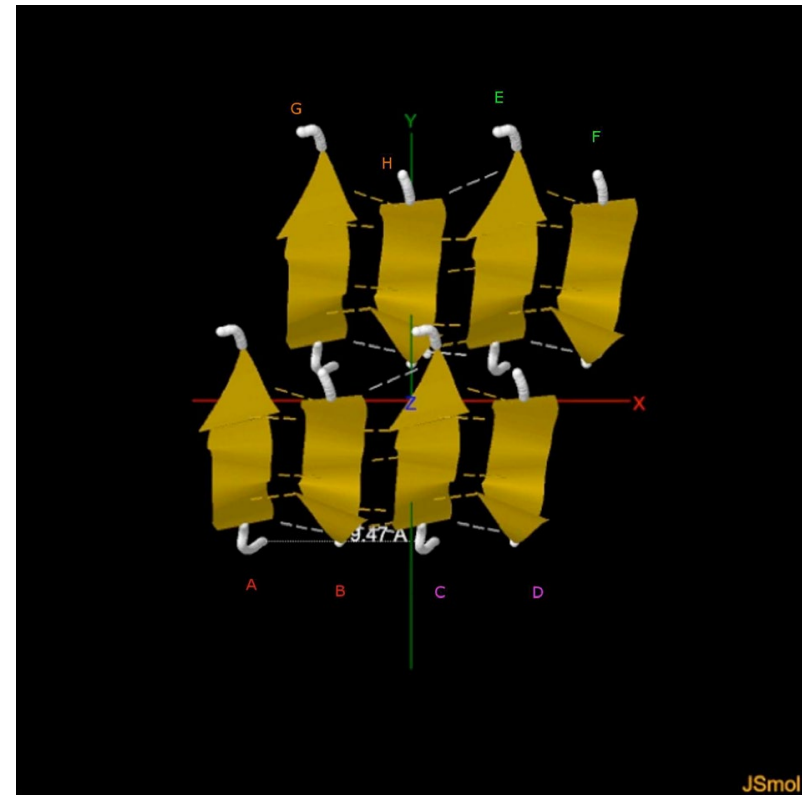

Figure 9: Protein fibril structure of human L129 prion GYLLGSA (127-133) (PDB ID: 4W71). The dashed lines denote the hydrogen bonds. A, B denote the basic chains of the fibril.

$$
E(F)(/ G(H))=\left(\begin{array}{lll}
1 & 0 & 0 \\
0 & 1 & 0 \\
0 & 0 & 1
\end{array}\right) A(B)+\left(\begin{array}{c}
13.36456(/ 3.89756) \\
9.62263 \\
0
\end{array}\right) .
$$

10. Figure 10, mathematical formulas for CD, EF, GH Chains obtained from the basic $\mathrm{AB}$ Chains respectively are

$$
\begin{aligned}
& C(D)=\left(\begin{array}{lll}
1 & 0 & 0 \\
0 & 1 & 0 \\
0 & 0 & 1
\end{array}\right) A(B)+\left(\begin{array}{c}
9.439 \\
0 \\
0
\end{array}\right), \\
& E(F)=\left(\begin{array}{lll}
-1 & 0 & 0 \\
0 & 1 & 0 \\
0 & 0 & -1
\end{array}\right) A(B)+\left(\begin{array}{c}
9.439 \\
8.896 \\
22.2805
\end{array}\right), \\
& G(H)=\left(\begin{array}{lll}
-1 & 0 & 0 \\
0 & 1 & 0 \\
0 & 0 & -1
\end{array}\right) A(B)+\left(\begin{array}{c}
18.878 \\
8.896 \\
22.2805
\end{array}\right) .
\end{aligned}
$$

11. Figure 11, mathematical formulas for $\mathrm{CD}, \mathrm{EF}, \mathrm{GH}$ Chains obtained from the basic $\mathrm{AB}$ Chains respectively are

$$
\begin{aligned}
& C(D)(/ E(F))=\left(\begin{array}{ccc}
1 & 0 & 0 \\
0 & 1 & 0 \\
0 & 0 & 1
\end{array}\right) A(B)+\left(\begin{array}{c}
-1.00212 \\
0(/-9.459 \\
19.64646
\end{array}\right), \\
& G(H)=\left(\begin{array}{lll}
1 & 0 & 0 \\
0 & 1 & 0 \\
0 & 0 & 1
\end{array}\right) A(B)+\left(\begin{array}{c}
0 \\
-9.459 \\
0
\end{array}\right) . \\
& \left(\begin{array}{lll}
-1 & 0 & 0 \\
0 & 1 & 0 \\
0 & 0 & -1
\end{array}\right) A(B)+\left(\begin{array}{c}
0 \\
4.7295 \\
0
\end{array}\right) .
\end{aligned}
$$




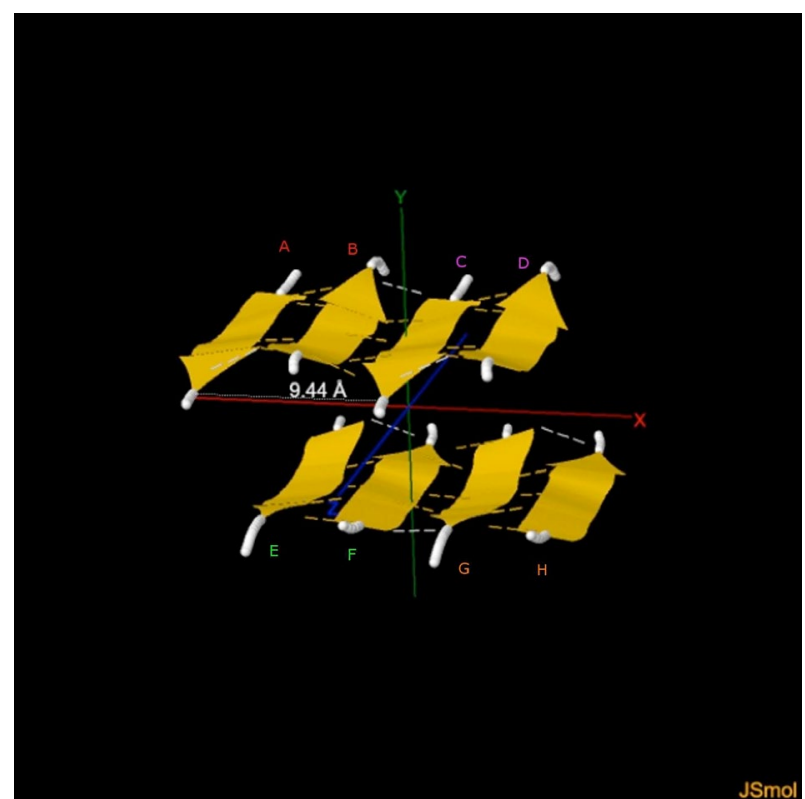

Figure 10: Protein fibril structure of human M129 prion GYMLGS (127-132) (PDB ID: 4WBU). The dashed lines denote the hydrogen bonds. A, B denote the basic chains of the fibril.

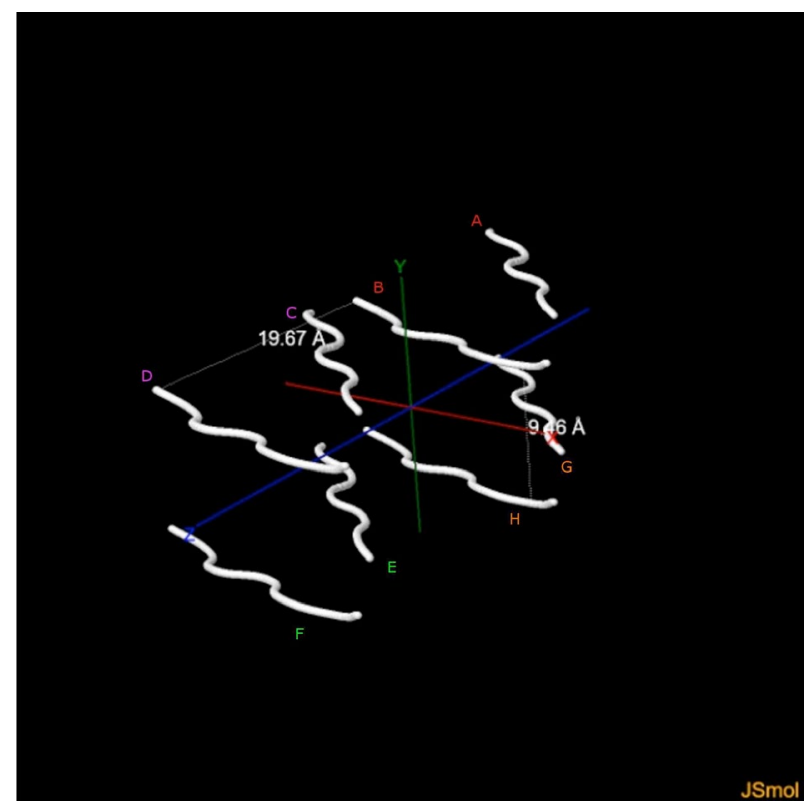

Figure 11: Protein fibril structure of human V129 prion GYVLGS (127-132) (PDB ID: 4WBV). A, B denote the basic chains of the fibril.

12. Figure 12, basing on $\mathrm{AB}$ Chains, other chains $\mathrm{CD}, \mathrm{EF}, \mathrm{GH}$ in the asym-metric one unit cell can be obtained by the mathematical formulas

$$
\begin{aligned}
& C(D)=\left(\begin{array}{lll}
-1 & 0 & 0 \\
0 & -1 & 0 \\
0 & 0 & 1
\end{array}\right) A(B)+\left(\begin{array}{c}
4.7195 \\
0 \\
22.2805
\end{array}\right), \\
& E(F)=\left(\begin{array}{lll}
-1 & 0 & 0 \\
0 & 1 & 0 \\
0 & 0 & -1
\end{array}\right) A(B)+\left(\begin{array}{c}
0 \\
8.896 \\
22.2805
\end{array}\right),
\end{aligned}
$$

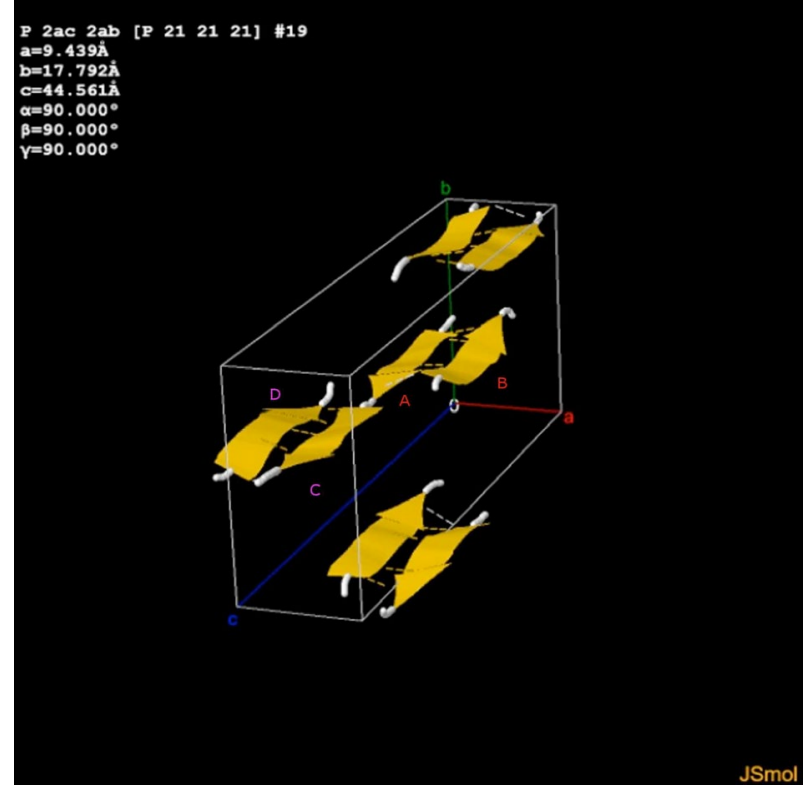

Figure 12: Protein fibril structure of human M129 prion GYMLGS (127-132) (PDB ID: 3MD4). The dashed lines denote the hydrogen bonds. A, B, C, D, E F, G, H denote the chains of the fibril.

$$
G(H)=\left(\begin{array}{lll}
1 & 0 & 0 \\
0 & -1 & 0 \\
0 & 0 & -1
\end{array}\right) A(B)+\left(\begin{array}{c}
4.7195 \\
8.896 \\
0
\end{array}\right) .
$$

13. Figure 13, basing on $\mathrm{AB}$ Chains, other Chains $\mathrm{CD}$ in the asymmetric unit cell can be obtained by mathematical formula

$$
C(D)=\left(\begin{array}{ccc}
-1 & 0 & 0 \\
0 & 1 & 0 \\
0 & 0 & -1
\end{array}\right) A(B)+\left(\begin{array}{c}
0 \\
4.7295 \\
0
\end{array}\right) .
$$

14. Figure 14 we see that $\mathrm{G}(\mathrm{H})$ chains (i.e., $\beta$-sheet 2 ) of 3 NHC.pdb can be obtained from $\mathrm{A}(\mathrm{B})$ chains (i.e., $\beta$-sheet 1 ) by

$$
G(H)=\left(\begin{array}{ccc}
1 & 0 & 0 \\
0 & -1 & 0 \\
0 & 0 & -1
\end{array}\right) A(B)+\left(\begin{array}{l}
9.07500 \\
4.77650 \\
0.00000
\end{array}\right),
$$

and other chains can be got by

$$
\begin{aligned}
& I(J)=G(H)+\left(\begin{array}{c}
0 \\
9.5530 \\
0
\end{array}\right), K(L)=G(H)+\left(\begin{array}{c}
0 \\
-9.5530 \\
0
\end{array}\right), \\
& C(D)=A(B)+\left(\begin{array}{c}
0 \\
9.5530 \\
0
\end{array}\right), E(F)=A(B)+\left(\begin{array}{c}
0 \\
-9.5530 \\
0
\end{array}\right) .
\end{aligned}
$$

15. By observations of the 3rd column of coordinates of 3NHD.pdb and Figure 15, G(H) chains (i.e., $\beta$-sheet 2) of 3NHD.pdb can be calculated from $\mathrm{A}(\mathrm{B})$ chains (i.e., $\beta$-sheet 1 ) by Equation (41) and other chains can be calculated by Equations (42) (43):

$$
\begin{aligned}
& G(H)=\left(\begin{array}{lll}
-1 & 0 & 0 \\
0 & 1 & 0 \\
0 & 0 & -1
\end{array}\right) A(B)+\left(\begin{array}{c}
-20.5865 \\
9.48 \\
0
\end{array}\right), \\
& K(L)=G(H)+\left(\begin{array}{l}
0 \\
0 \\
9.59
\end{array}\right), I(J)=G(H)+\left(\begin{array}{c}
0 \\
0 \\
-9.59
\end{array}\right),
\end{aligned}
$$




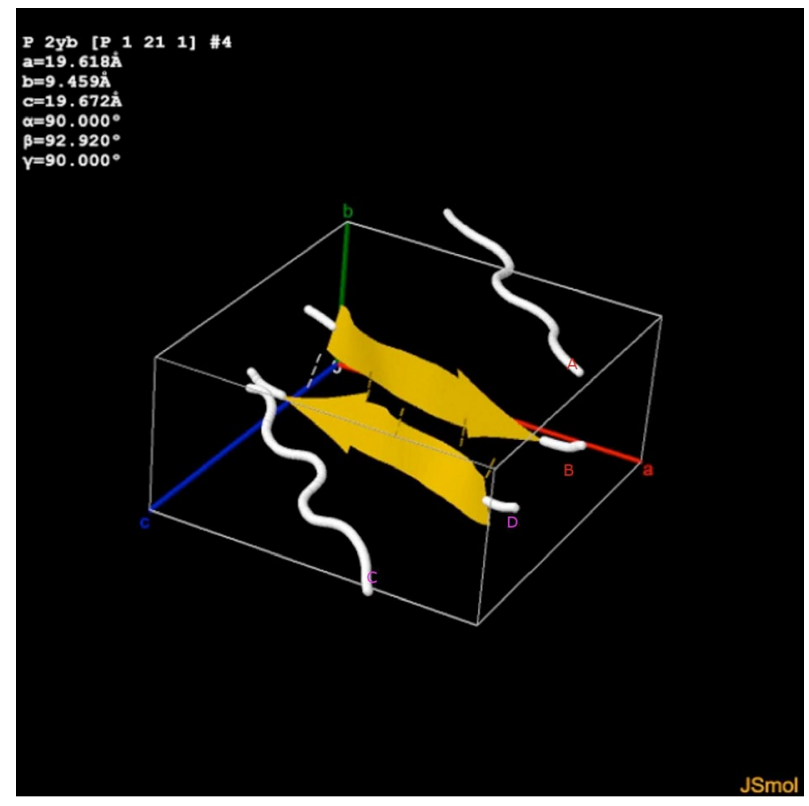

Figure 13: Protein fibril structure of human V129 prion GYMLGS (127-132) (PDB ID: 3MD5). The dashed lines denote the hydrogen bonds. A, B, C, D denote the chains of the fibril.

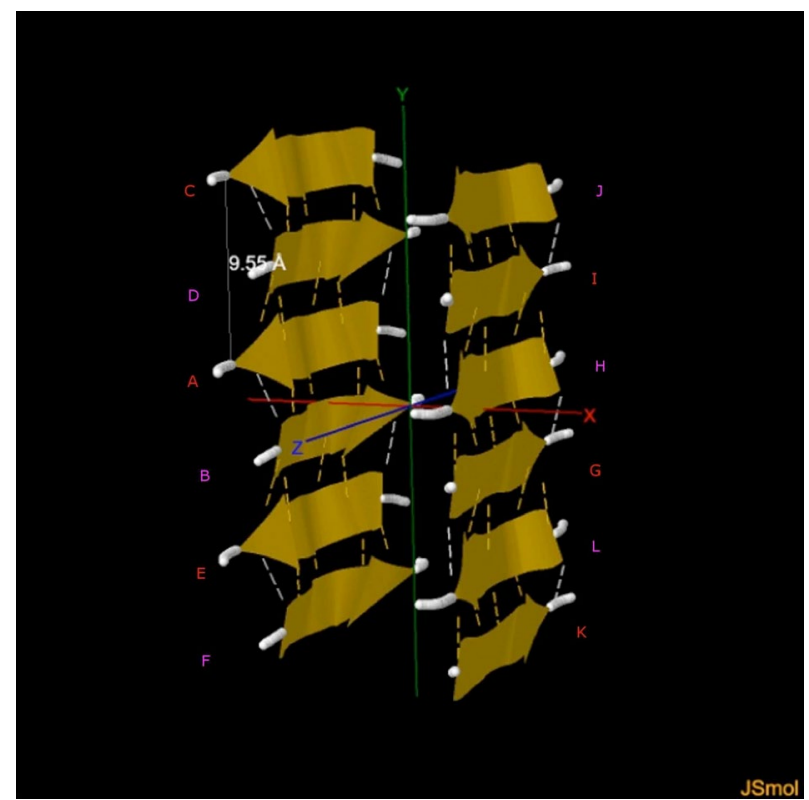

Figure 14: Protein fibril structure of human M129 prion GYMLGS (127-132) (PDB ID: 3NHC). The dashed lines denote the hydrogen bonds. A, B ... K, L denote the chains of the fibril.

$$
C(D)=A(B)+\left(\begin{array}{c}
0 \\
0 \\
9.59
\end{array}\right), E(F)=A(B)+\left(\begin{array}{c}
0 \\
0 \\
-9.59
\end{array}\right) .
$$

16.In Figure 16 we see that $\mathrm{H}$ Chain (i.e., $\beta$-sheet 2 ) of $3 \mathrm{NVG}$.pdb can be obtained from A Chain (i.e., $\beta$-sheet 1 ) by

$$
H=\left(\begin{array}{lll}
-1 & 0 & 0 \\
0 & 1 & 0 \\
0 & 0 & -1
\end{array}\right) A+\left(\begin{array}{c}
-27.28 \\
2.385 \\
15.738
\end{array}\right),
$$

and other chains can be got by

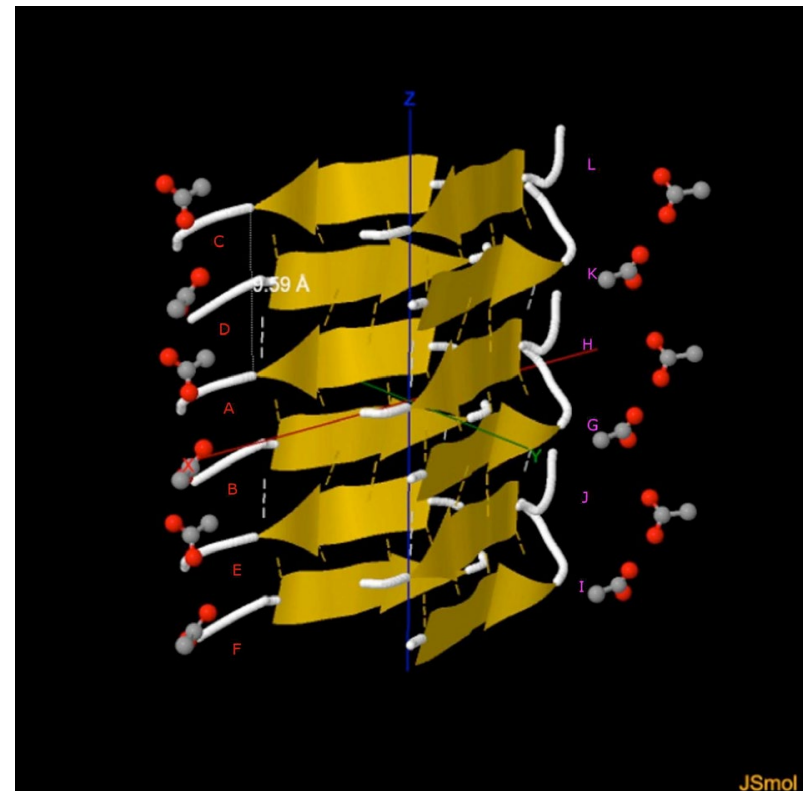

Figure 15: Protein fibril structure of human V129 prion GYVLGS (127-132 (PDB ID: 3NHD). The dashed lines denote the hydrogen bonds. A, B ... K, L denote the chains of the fibril.

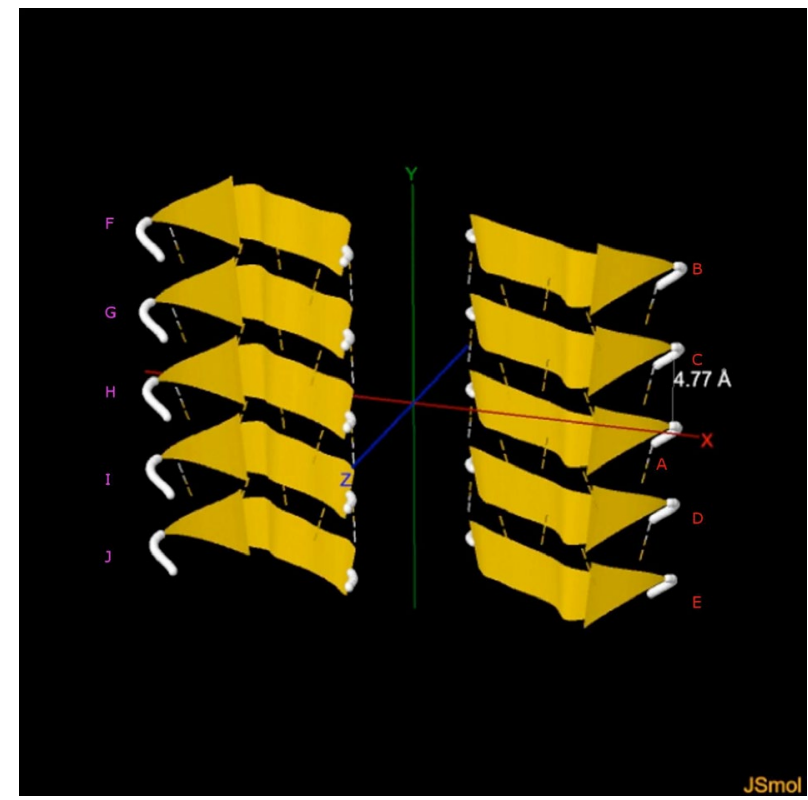

Figure 16: Protein fibril structure of MIHFGN segment 137-142 from mouse prion (PDB ID: 3NVG). The purple dashed lines denote the hydrogen bonds $A, B, \ldots, I, J$ denote the 10 chains of the fibril.

$$
\begin{aligned}
& C(G)=A(H)+\left(\begin{array}{l}
0 \\
4.77 \\
0
\end{array}\right), B(F)=A(H)+2\left(\begin{array}{c}
0 \\
4.77 \\
0
\end{array}\right), \\
& D(I)=A(H)-\left(\begin{array}{c}
0 \\
4.77 \\
0
\end{array}\right), E(J)=A(H)-2\left(\begin{array}{c}
0 \\
4.77 \\
0
\end{array}\right) .
\end{aligned}
$$

17.In Figure 17 we see that $\mathrm{H}$ chain (i.e., $\beta$-sheet 2 ) of $3 \mathrm{NVH}$.pdb can be obtained from $A$ chain (i.e., $\beta$-sheet 1 ) by 
Citation: Zhang J (2016) Mathematical Formulas for Prion All Cross-Structures Listed in the Protein Data Bank. Med chem (Los Angeles) 6: 179-188. doi:10.4172/2161-0444.1000343

$$
H=\left(\begin{array}{lll}
-1 & 0 & 0 \\
0 & 1 & 0 \\
0 & 0 & -1
\end{array}\right) A+\left(\begin{array}{c}
0 \\
2.437 \\
-15.553
\end{array}\right)
$$

and other chains can be got by

$$
\begin{aligned}
& C(G)=A(H)+\left(\begin{array}{c}
0 \\
4.87 \\
0
\end{array}\right), B(F)=A(H)+2\left(\begin{array}{c}
0 \\
4.87 \\
0
\end{array}\right), \\
& D(I)=A(H)-\left(\begin{array}{c}
0 \\
4.87 \\
0
\end{array}\right), E(J)=A(H)-2\left(\begin{array}{c}
0 \\
4.87 \\
0
\end{array}\right) .
\end{aligned}
$$

18. In Figure 18 we see that $\mathrm{G}(\mathrm{H})$ chains (i.e., $\beta$-sheet 2 ) of $3 \mathrm{NVE.pdb}$ can be obtained from $\mathrm{A}(\mathrm{B})$ chains (i.e., $\beta$-sheet 1 ) by

$$
G(H)=A(B)+\left(\begin{array}{c}
0 \\
11.784 \\
0
\end{array}\right),
$$

and other chains can be got by

$$
\begin{aligned}
& C(D)=A(B)+\left(\begin{array}{c}
9.513 \\
0 \\
0
\end{array}\right), E(F)=A(B)+\left(\begin{array}{c}
-9513 \\
0 \\
0
\end{array}\right), \\
& J(I)=H(G)+\left(\begin{array}{c}
9.513 \\
0 \\
0
\end{array}\right), L(K)=H(G)+\left(\begin{array}{c}
-9513 \\
0 \\
0
\end{array}\right) .
\end{aligned}
$$

19.In Figure 19 we see that $H$ chain (i.e., $\beta$-sheet 2) of $3 N V F . p d b$ can be obtained from $A$ chain (i.e., $\beta$-sheet 1 ) by

$$
H=\left(\begin{array}{lll}
-1 & 0 & 0 \\
0 & -1 & 0 \\
0 & 0 & 1
\end{array}\right) A+\left(\begin{array}{c}
27.546 \\
0 \\
0
\end{array}\right),
$$

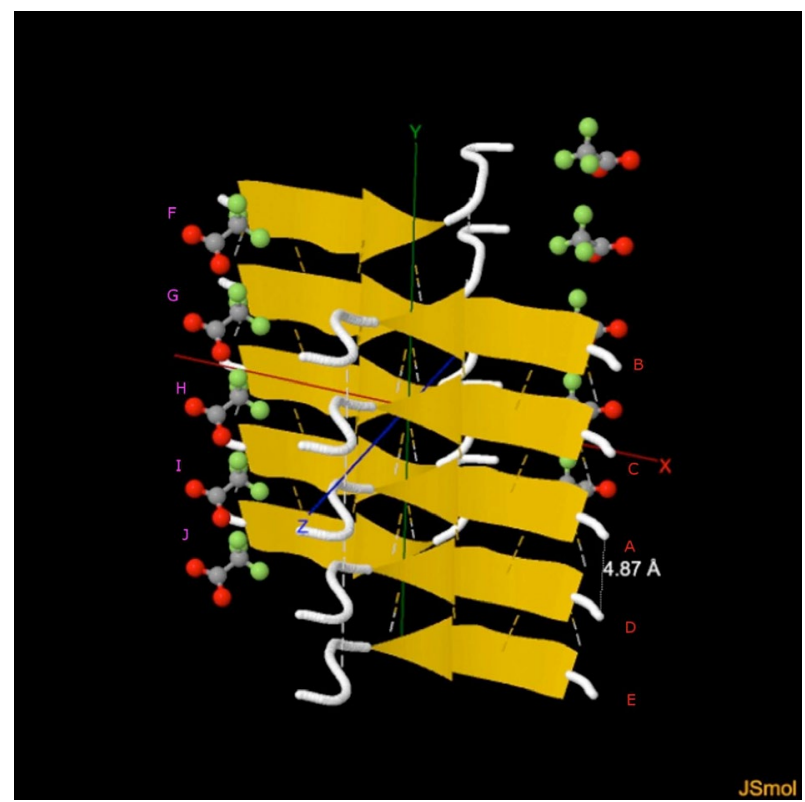

Figure 17: Protein fibril structure of MIHFGND segment 137-143 from mouse prion (PDB ID: $3 \mathrm{NVH}$ ). The purple dashed lines denote the hydrogen bonds. $A, B, \ldots, I, J$ denote the 10 chains of the fibril.

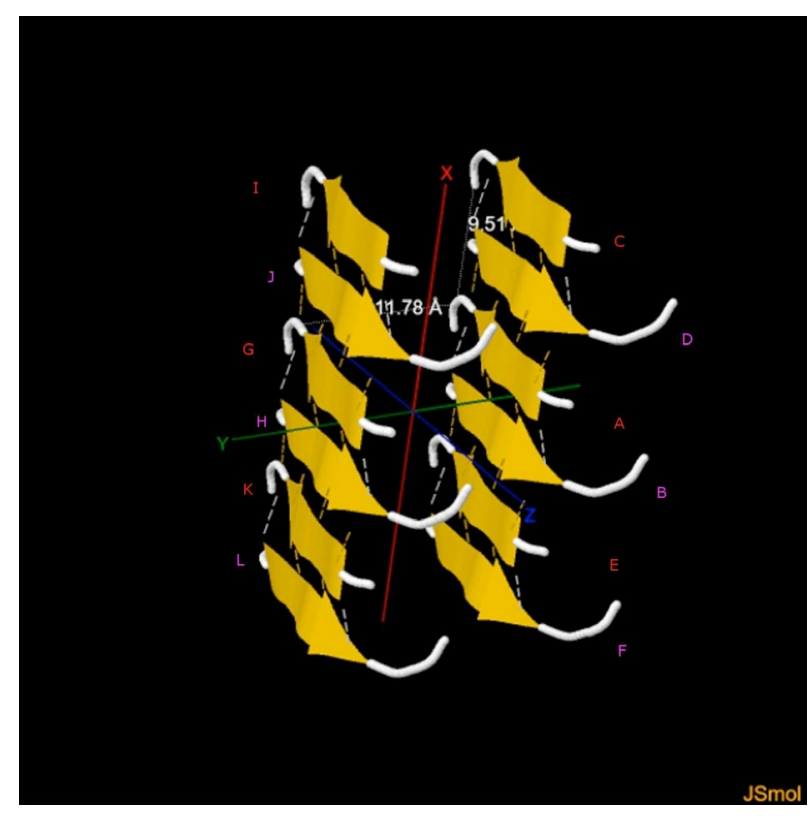

Figure 18: Protein fibril structure of MMHFGN segment 138-143 from Syrian Hamster prion (PDB ID: 3NVE). The purple dashed lines denote the hydrogen bonds. $A, B, \ldots, K, L$ denote the 12 chains of the fibril.

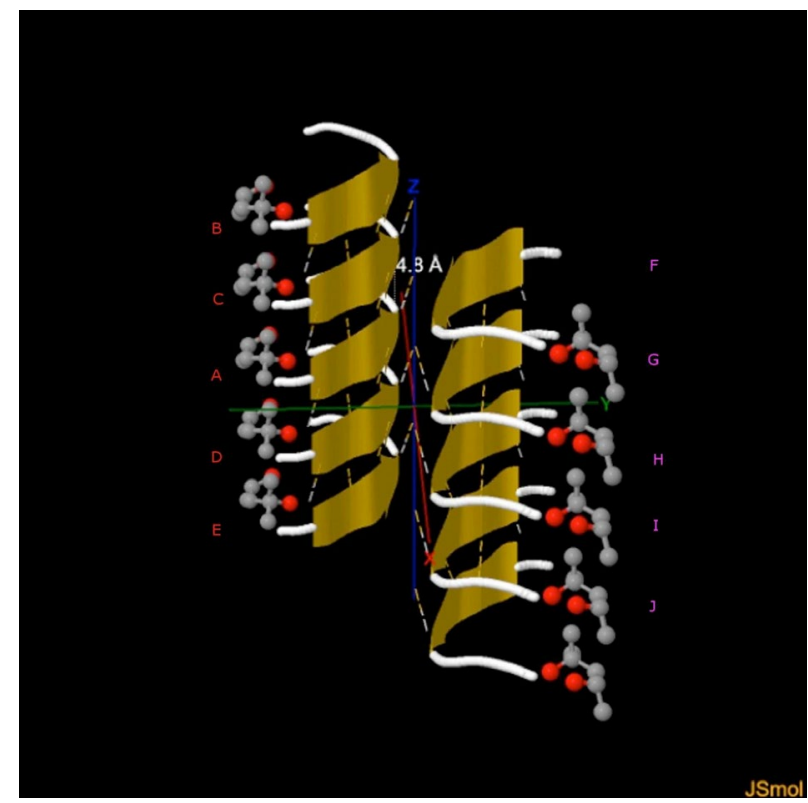

Figure 19: Protein fibril structure of IIHFGS segment 138-143 from human prion (PDB ID: 3NVF). The purple dashed lines denote the hydrogen bonds. A $B, \quad J, J$ denote the 10 chains of the fibrils.

and other chains can be got by

$$
\begin{gathered}
C(G)=A(H)+\left(\begin{array}{c}
0 \\
0 \\
4.8
\end{array}\right), B(F)=A(H)+2\left(\begin{array}{c}
0 \\
0 \\
4.8
\end{array}\right), \\
D(I)=A(H)-\left(\begin{array}{c}
0 \\
0 \\
4.8
\end{array}\right), E(J)=A(H)-2\left(\begin{array}{c}
0 \\
0 \\
4.8
\end{array}\right) .
\end{gathered}
$$

20. Figure 20 .

21. In Figure 21, we see that the D chain (i.e., $\beta$-sheet 2) of 2OL9.pdb can 


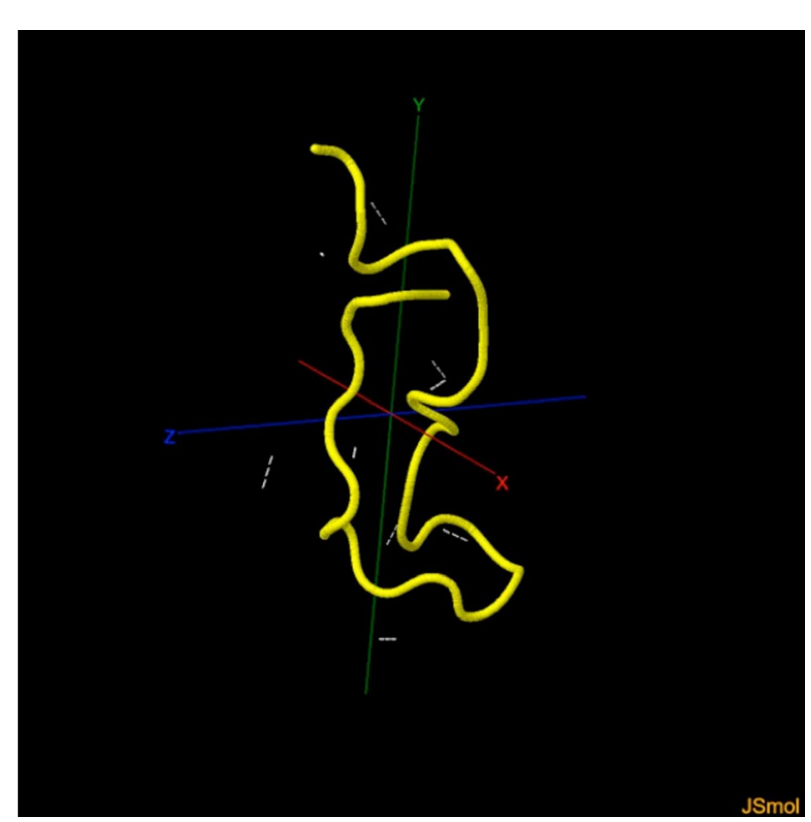

Figure 20: Protein $\beta$-hairpin structure of segment 142-166 from sheep prion (PDB ID: 1G04). The dashed lines denote the hydrogen bonds.

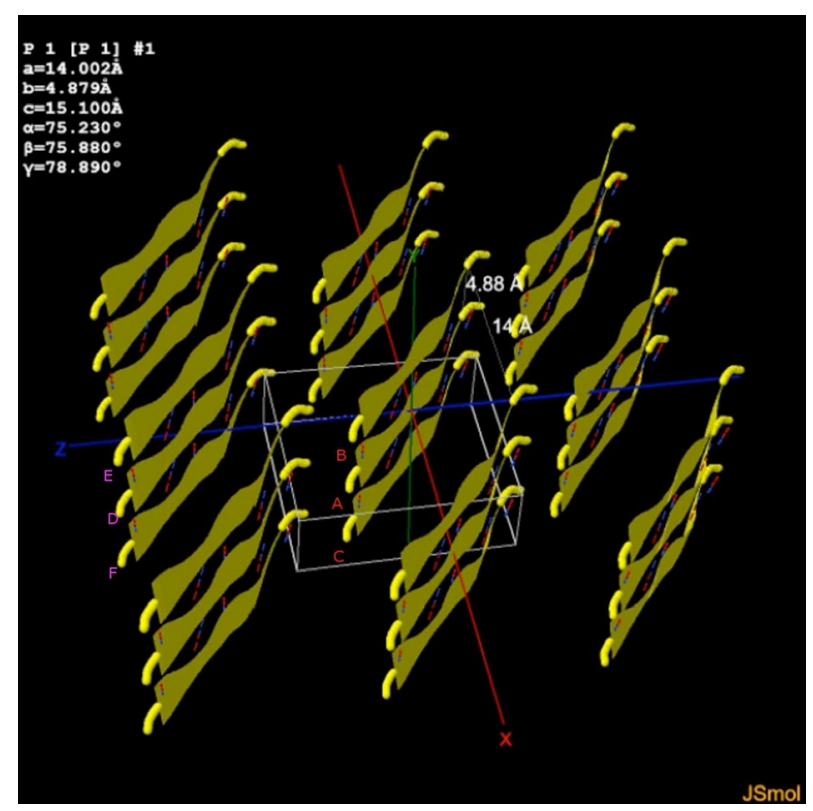

Figure 21: Protein fibril structure of NNQNTF segment 170-175 from human prion (PDB ID: 2OL9). The dashed lines denote the hydrogen bonds. A, B, C $D, E, F$ denote the 6 chains of the fibrils.

be obtained from A Chain (i.e., $\beta$-sheet 1 ) using the mathematical formula

$$
D=\left(\begin{array}{lll}
1 & 0 & 0 \\
0 & 1 & 0 \\
0 & 0 & 1
\end{array}\right) A+\left(\begin{array}{c}
0.94015 \\
4.78756 \\
0
\end{array}\right),
$$

and other chains can be got by

$$
B(E)=A(D)+\left(\begin{array}{c}
0 \\
4.88 \\
0
\end{array}\right)
$$

$$
C(F)=A(D)-\left(\begin{array}{c}
0 \\
4.88 \\
0
\end{array}\right) .
$$

22.In Figure 22, we see that the D chain (i.e., $\beta$-sheet 2) of 3FVA. pdb can be obtained from A Chain (i.e., $\beta$-sheet 1 ) using the mathematical formula

$$
D=\left(\begin{array}{lll}
-1 & 0 & 0 \\
0 & 1 & 0 \\
0 & 0 & -1
\end{array}\right) A+\left(\begin{array}{c}
-14.31482 \\
2.42 \\
-21.03096
\end{array}\right),
$$

and other chains can be got by

$$
\begin{gathered}
B(E)=A(D)+\left(\begin{array}{c}
0 \\
4.88 \\
0
\end{array}\right), \\
C(F)=A(D)-\left(\begin{array}{c}
0 \\
4.88 \\
0
\end{array}\right) .
\end{gathered}
$$

23. Figure 23.

\section{Figure 24.}

All the above X-ray crystallography structures show to us, in the $\operatorname{PrP}(119-231)$ structured region, there are many segments of peptides which can formulate into amyloid fibrils. The author's theoretical calculations [5,6] (Figures 25 and 26, where $-26 \mathrm{kcal} / \mathrm{mol}$ is the threshold energy of amyloid fibril formation: if energy is less than $-26 \mathrm{kcal} / \mathrm{mol}$ it will have amyloid fibril forming property [7]) also show this point.

Last, seeing Figure 26, we may think there must be a laboratory $\mathrm{X}$-ray crystal $\beta$-type structure in $\operatorname{PrP}(184-192)$ segment that will be produced by a X-ray lab in the near future.

In conclusion, this short article described about the comparison study of theoretical calculations and X-ray crystallography study

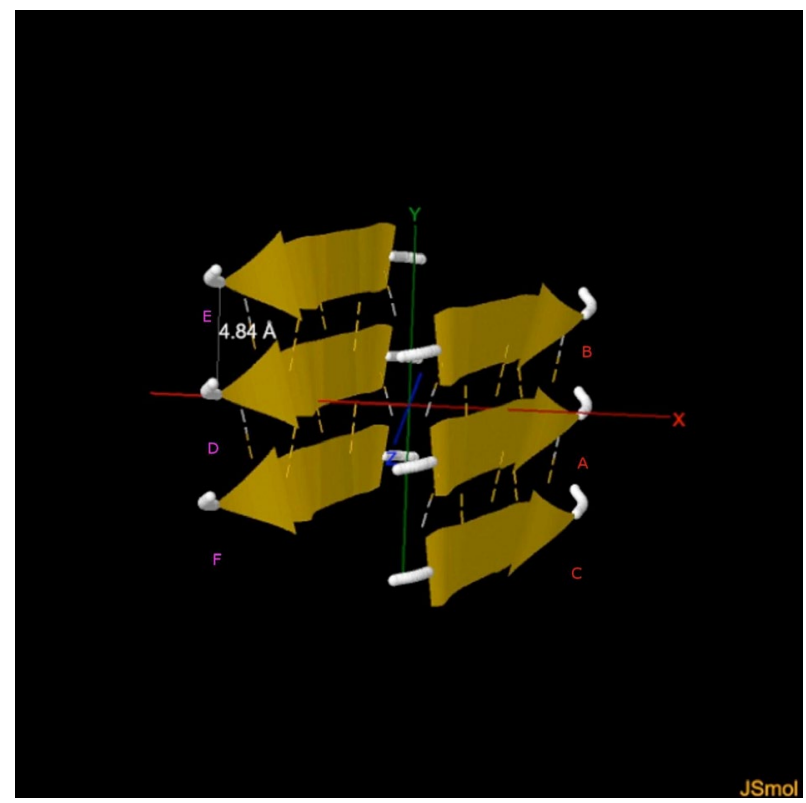

Figure 22: Protein fibril structure of NNQNTF segment 170-175 from elk prion (PDB ID: 3FVA). The dashed lines denote the hydrogen bonds. A, B, C $D, E, F$ denote the 6 chains of the fibrils. 
Citation: Zhang J (2016) Mathematical Formulas for Prion All Cross-Structures Listed in the Protein Data Bank. Med chem (Los Angeles) 6: 179-188. doi:10.4172/2161-0444.1000343

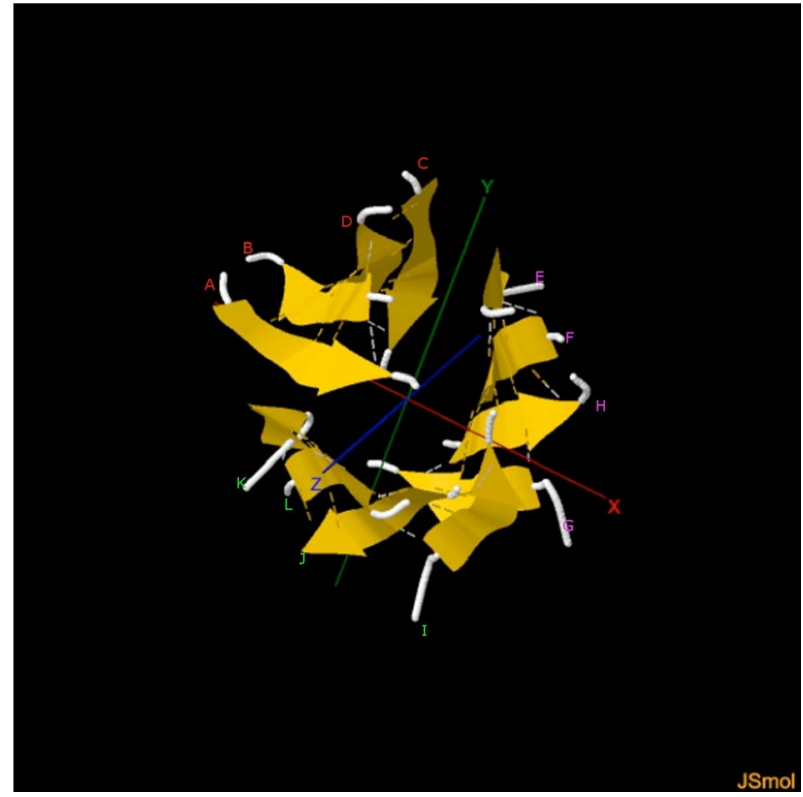

Figure 23: Protein $\beta$-prism fibril structure of segments 177-182, 211-216 from human prion (PDB ID: 4E1I). The dashed lines denote the hydrogen bonds. A, B, C, D, E, F, G, H, I, J, K, L denote the 12 chains of the fibrils.

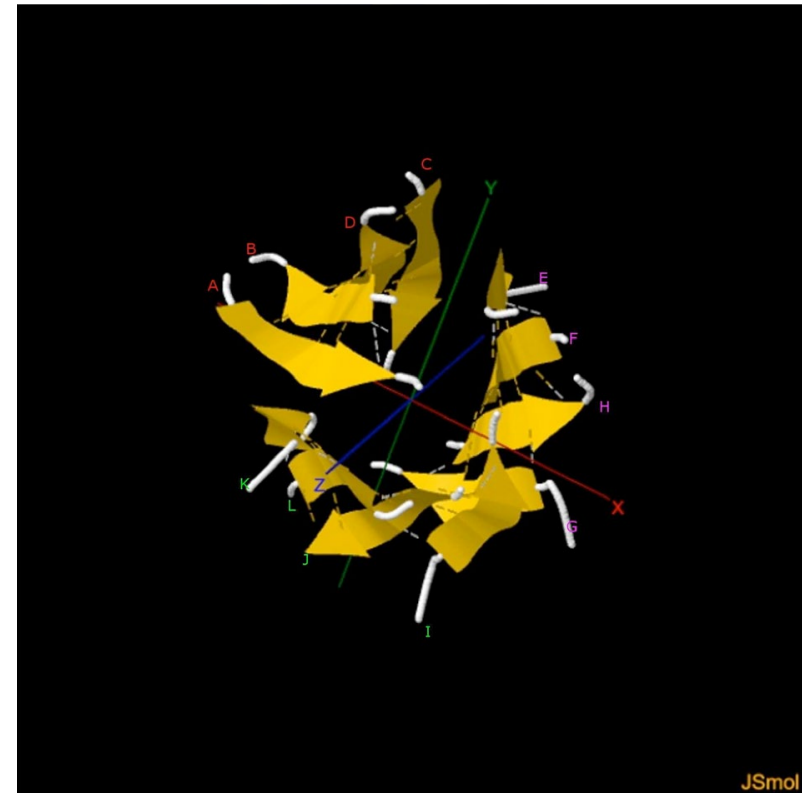

Figure 24: Protein $\beta$-prism fibril structure of segments 177-182, 211-216 from human prion (PDB ID: 4E1H). The dashed lines denote the hydrogen bonds. A, B, C, D, E, F, G, H, I, J, K, L denote the 12 chains of the fibrils.
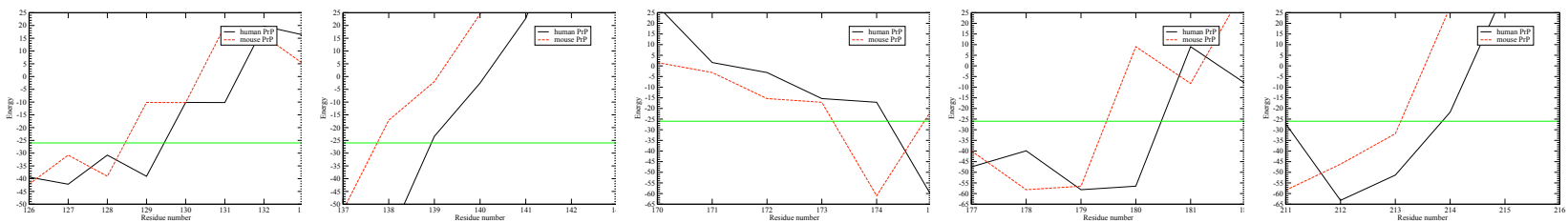

Figure 25: By theoretical calculations of the author, $\operatorname{PrP}(126-133), \operatorname{PrP}(137-143), \operatorname{Pr}(170-175), \operatorname{Pr} P(177-182), \operatorname{Pr} P(211-216)$ were identified owning the amyloid fibril forming property respectively (the graphs from left to right).

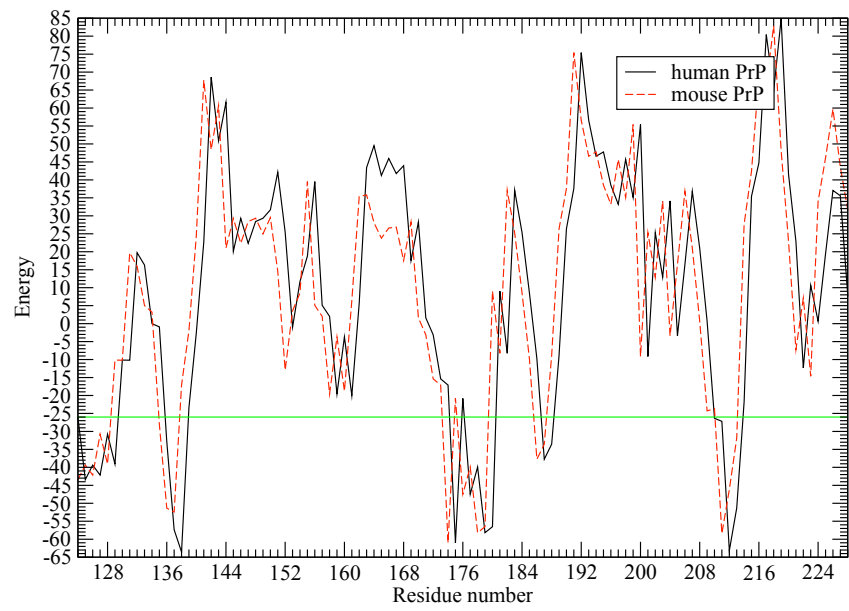

Figure 26: To identify the segments owning the amyloid fibril forming property in the whole PrP structured region: if the energy is less than $-26 \mathrm{kcal} / \mathrm{mol}$ it will have amyloid fibril forming property [7]

of prion protein cross-beta structures. The author has very good prediction of theoretical calculations using mathematical formulas of unstructured region and structured region of prion proteins in detail well demonstrated. Moreover, the X-ray crystallography structures showed, in the $\operatorname{PrP}(119-231)$ structured region, there are many segments of peptides which can formulate into amyloid fibrils. The author's theoretical calculations for Figures 25 and 26 were shown threshold energy as $-26 \mathrm{kcal} / \mathrm{mol}$, which supports to the amyloid fibril formation. Even if the threshold energy is less than $-26 \mathrm{kcal} / \mathrm{mol}$ also they will have amyloid fibril forming property. This is a good piece of work useful for the medicinal chemists. The author presented the results very well in the article, and provided an introduction of the structures to understand the significance in the biological use of amyloid fibrils [8-14].

\section{Acknowledgements}

This research was supported by a Victorian Life Sciences Computation Initiative (VLSCI) grant numbered FED0001 on its Peak Computing Facility at the University of Melbourne, an initiative of the Victorian Government (Australia). The author also acknowledges the anonymous referees for their numerous insightful comments and references [8-14] offered.

\section{References}

1. Sawaya MR, Sambashivan S, Nelson R, Ivanova MI, Sievers SA, et al. (2007) Atomic structures of amyloid cross- $ß$ spines reveal varied steric zippers. Nature 447: 453-457.

2. Apostol MI, Perry K, Surewicz WK (2013) Crystal structure of a human prion protein fragment reveals a motif for oligomer formation. J Am Chem Soc 135: 10202-10205.

3. Kozin SA, Bertho G, Mazur AK, Rabesona H, Girault JP, et al. (2001) Sheep 
Citation: Zhang J (2016) Mathematical Formulas for Prion All Cross-Structures Listed in the Protein Data Bank. Med chem (Los Angeles) 6: $179-188$. doi:10.4172/2161-0444.1000343

prion protein synthetic peptide spanning helix 1 and beta-strand 2 (residues 142-166) shows beta-hairpin structure in solution. J Biol Chem 276: 4636446370

4. Yu L, Lee SJ, Yee VC (2015) Crystal structures of polymorphic prion protein ß1 peptides reveal variable steric zipper conformations. Biochemistry 54: 3640 3648.

5. Zhang JP (2011) Practical Global Optimization Computing Methods in Molecular Modelling - for Atomic-resolution Structures of Amyloid Fibrils, LAP LAMBERT Academic Publishing, ISBN 978-3-8465-2139-7.

6. Zhang JP (2015) Molecular Structures and Structural Dynamics of Prion Proteins and Prions - Mechanism Underlying the Resistance to Prion Diseases, Springer, ISBN 978-94-017-7317-1.

7. Zhang Z, Chen H, Lai L (2007) Identification of amyloid fibril-forming segments based on structure and residue-based statistical potential. Bioinformatics 23: 2218-2225.

8. Rajagopal A, Aravinda S, Raghothama S, Shamala N, Balaram P (2011) Chain length effects on helix-hairpin distribution in short peptides with Aib-DAla and Aib-Aib segments. Biopolymers 96: 744-756.
9. Raghavender US, Chatterjee B, Saha I, Rajagopal A, Shamala N, et al. (2011) Entrapment of a water wire in a hydrophobic peptide channel with an aromatic lining. J Phys Chem B 115: 9236-9243.

10. Rajagopal A, Aravinda S, Raghothama S, Shamala N, Balaram P (2012) Aromatic interactions in model peptide $\beta$-hairpins: ring current effects on proton chemical shifts. Biopolymers 98: 185-194.

11. Basuroy K, Rajagopal A, Raghothama S, Shamala N, Balaram P (2012) $\beta$-Turn analogues in model $\alpha \beta$-hybrid peptides: structural characterization of peptides containing $\beta(2,2) A c 6 c$ and $\beta(3,3) A c 6 c$ residues. Chem Asian J 7: 1671-1678.

12. Rajagopal A, Charles BC, Alexey YK, Joshua DS, Frederick JK, et al. (2015) Enhancing the magnitude of antibody responses through biomaterial stereochemistry. ACS Biomater Sci Eng 1: 601-609.

13. Alexey YK, Rajagopal A, Samantha S, Jai SR (2015) Self-assembly of heterochiral peptides with varied sequence patterns.

14. Rudra JS, Ding Y, Neelakantan H, Ding C, Appavu R, et al. (2016) Suppression of Cocaine-Evoked Hyperactivity by Self-Adjuvanting and Multivalent Peptide Nanofiber Vaccines. ACS Chem Neurosci. 